\section{Heart rate variability for small animal veterinarians - A concise debate}

\author{
Variabilidade da Frequência Cardíaca para os clínicos de \\ pequenos animais - Um breve debate
}

Luciano Gonçalves Fernandes ${ }^{1 *}$ and Fernando de Azevedo Cruz Seara

1. Veterinarian, DSc., Departamento de Ciências Fisiológicas,Instituto de Ciências Biológicas e da Saúde, Universidade Federal Rural do Rio de Janeiro. Campus Seropédica - RJ, Brazil

\begin{abstract}
This manuscript aims to provide a simple and concise discussion on heart rate variability (HRV) for small animal veterinarians. Despite the fact that heart rate variability analysis techniques have been used for quite a long time in medical sciences, it seems to be not completely understood by a large fraction of veterinarian professionals, thereby, reducing the possible benefits to patients that could arise from such information. The analysis of the R-R intervals enables the veterinarian to evaluate autonomic sympathetic and parasympathetic modulation of the heart, composing the so-called cardiac autonomic balance. Several pathophysiological states lead to profound changes in autonomic balance, especially in the cardiovascular system. Therefore, heart rate variability methods remain a valuable and powerful tool for the diagnosis and prognosis of cardiovascular diseases.
\end{abstract}

Keywords: heart rate variability, veterinary cardiology, autonomic nervous system, small animals, cardiac interval.

\section{Resumo}

Esta revisão tem como objetivo fornecer uma discussão breve e simples acerca da variabilidade da frequência cardíaca (VFC) para veterinários de pequenos animais. Apesar de as técnicas de análise da variabilidade da frequência cardíaca já serem utilizadas há bastante tempo nas ciências médicas, aparentemente não são totalmente compreendidas por grande parte dos profissionais veterinários, reduzindo, assim, os possíveis benefícios aos pacientes que poderiam advir de tais informações. A análise dos intervalos R-R permite ao veterinário avaliar a modulação autonômica simpática e parassimpática do coração, compondo o chamado equilibrio autonômico cardíaco. Vários estados fisiopatológicos levam a profundas alterações no equilíbrio autonômico, especialmente no sistema cardiovascular. Portanto, os métodos de variabilidade da frequência cardíaca representam uma ferramenta valiosa para o diagnóstico e prognóstico de doenças cardiovasculares.

Palavras-chave: variabilidade da frequência cardíaca, cardiologia veterinária, sistema nervoso autônomo, pequenos animais, intervalo cardíaco.

\section{Aim}

The main aim of this study was to provide a simple and concise discussion about the main methods currently used to evaluate heart rate variability in small animals. Moreover, this manuscript attempts to explain the meaning and significance of the most used HRV analysis methods, as well as refers to the literature in order to allow further comparisons in daily clinical practice (for this matter, this manuscript includes mainly veterinary clinical studies). Finally, the limitations of the main methods are considered, as well as alternative and future prospects.

\section{Heart rate variability}

Within a certain period of time, it is possible to determine systolic cardiac frequency from an animal by counting the number of heartbeats that occur, for example, within a minute. This would result in a number, commonly called heart rate. However, if one measures the duration of the interval between each cardiac contraction in the same sample, it is possible to observe that this interval is not constant, meaning that the heart rate oscillates over time. Heart rate variability refers to the oscillation of the time interval observed between consecutive heartbeats (Shaffer \&
How to cite: Fernandes, L. G., \& Seara, F. A. C. (2021). Heart rate variability for small animal veterinarians - A concise debate. Brazilian Journal of Veterinary Medicine, 43, e003621. https://doi. org/10.29374/2527-2179.bjvm003621

Received: September 16, 2021.

Accepted: October 01, 2021.

\section{*Correspondence}

Luciano Gonçalves Fernandes

Departamento de Ciências Fisiológicas, Instituto de Ciências Biológicas e da Saúde, Universidade Federal Rural do Rio de Janeiro - UFRRJ

Rodovia BR 465, Km 7, Campus Universitário, Bairro Zona Rural

CEP 23897-000 - Seropédica (RJ), Brasil

E-mail: fernandeslg@gmail.com
Copyright Fernandes et al. This is an Open Access article distributed under the terms of the Creative Commons Attribution Non-Commercial License, which permits unrestricted non-commercial use, distribution and reproduction in any medium provided the original work is properly cited. 
Ginsberg, 2017). However, this expression has also been used to indicate the oscillation between consecutive instantaneous heart rates, which is not exactly the same as two consecutive heartbeats (Task Force of the European Society of Cardiology, 1996). HRV is a variable of the cardiovascular system that acts at several time scales to adapt the system to several challenges and stimuli (Task Force of the European Society of Cardiology, 1996; Shaffer \& Ginsberg, 2017). Although there are many terms in the literature to indicate the time intervals between two cardiac contractions, the terminology HRV is widely accepted and therefore will be used henceforth.

\section{HRV importance, applications, and potentialities}

Several cardiovascular physiological and pathophysiological states change the autonomic balance to the heart. This altered state in autonomic cardiac activity leads to a modification in the pattern of R-R interval oscillation (Shaffer \& Ginsberg, 2017). For example, a hemorrhage could lead to baroreceptor deactivation, which in turn would increase sympathetic activity and decrease parasympathetic activity to the heart, resulting in a shortening of the R-R interval (Jiménez et al., 2001). This example illustrates how a sympathetic increase/parasympathetic decrease is perceived by observing the R-R intervals. In medical sciences, HRV analysis has been used to evaluate the effect of the state of autonomic nervous system modulation on the heart, to predict both incidence of and mortality due to arrhythmias and myocardial infarction, and to evaluate the state of diabetes and renal failure, among several other potential factors (Rajendra Acharya et al., 2006). In small animal veterinary medicine, the potential benefits of HRV analysis depend on a more frequent clinical evaluation of HRV. For example, Borgarelli et al. (2020) recognized that there were two phenotypes of dogs with degenerative mitral valve disease (DMVD): dogs that would be treated and live for many years with the disease, and those that would progress abruptly to cardiac death. Perhaps, HRV analysis may help us investigate whether there is a distinct neurohumoral activation of the cardiovascular system in these two phenotypes of dogs with DMVD.

\section{HRV measurement}

The first step in evaluating HRV is to build an R-R interval histogram. This is a very useful visual method to inspect HRV. The RR interval histogram is obtained by enlisting all the intervals between two consecutive R waves from the electrocardiogram (ECG) and then plotting these values in a graph where the $\mathrm{x}$-axis shows the R-R interval and the $\mathrm{y}$-axis stands for the number of occurrences of each R-R interval. Figure 1 illustrates this process of obtaining the interval histogram. From this point, there are two main methods for the evaluation of HRV, which are widely used nowadays: $a$ ) the time domain and b) the frequency domain, as depicted below:

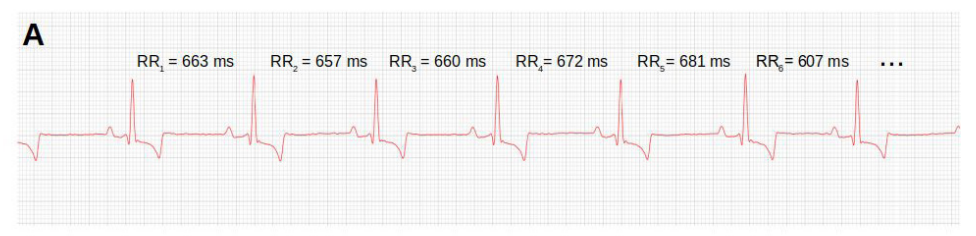

\begin{tabular}{|c|c|}
\hline R-R & $\begin{array}{l}\text { Duration } \\
\text { (ms) }\end{array}$ \\
\hline 1 & 663 \\
\hline 2 & 657 \\
\hline 3 & 660 \\
\hline 4 & 672 \\
\hline 5 & 681 \\
\hline 6 & 607 \\
\hline
\end{tabular}

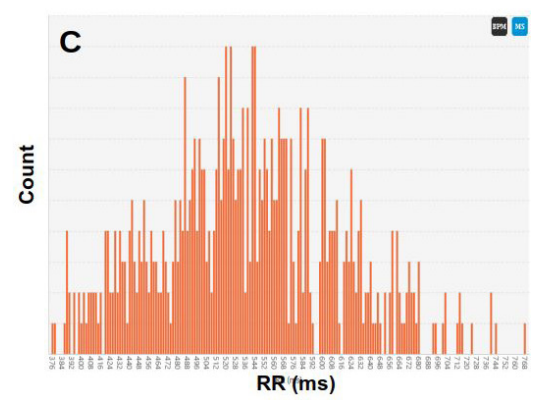

Figure 1. ECG tracing (A) showing consecutives R-R intervals enlisted in a table (B) that in turn is used to plot the interval histogram or density plot (C). Through this graph it is possible to visually inspect the HRV. Most time domain methods are derived from the statistical properties of the time series or from geometrical properties of the density plot. 


\section{Time domain methods:}

This set of techniques is the simplest form of evaluating HRV; therefore, it is advantageous. However, these techniques convey less information and insights about the pathophysiological state of patients when compared to the frequency domain method (Task Force of the European Society of Cardiology, 1996). In the time domain, there are two subsets of techniques that are used to evaluate HRV: statistical and geometrical methods (Task Force of the European Society of Cardiology, 1996; Shaffer \& Ginsberg, 2017). Statistical methods have an origin in the determination of variables commonly used by the statistics (therefore called statistical methods), while the geometrical methods are based on the geometrical characteristics of the graph generated by the HRV analysis, for instance, the data interval (range) observed in an R-R histogram (Hezzell et al., 2018).

As a general procedure, the $\mathrm{R}$ waves are automatically detected from the electrocardiogram (ECG) recording, and the time interval between every two consecutive $\mathrm{R}$ waves is determined (R-R interval). As a result, a table can be built enlisting every specific R-R interval and its duration, and this table is generally called a time series (Rajendra Acharya et al., 2006). Eventually, in the resulting temporal series, it is possible to observe the variation in the R-R time interval along the recording time (therefore, in the time domain). The time series can be used to compute data according to different algorithms (statistical or geometrical). In small animal veterinary medicine, five statistical methods are widely used to estimate the state of cardiac regulatory mechanisms (Blake et al., 2018). Information on the main time domain techniques is listed below:

a) The standard deviation of $N$ consecutive $R$-R intervals (SDNN) represents the dispersion of the length of the cardiac cycle around its mean value and is measured in milliseconds (ms). SDNN is an important measurement of HRV because, in mathematical terms, the standard deviation of subsequent $R$-R intervals is related to the variance of HRV, which in turn represents the total power of the HRV (TP) over the recording period (Rajendra Acharya et al., 2006; Shaffer \& Ginsberg, 2017). Reduced SDNN values indicate reduced autonomic modulation of the heart, with a predominance of either sympathetic or parasympathetic activity (Fujii \& Wakao, 2003). It should also be emphasized that SDNN is greatly affected by the shortest and longest R-R interval in the time series; therefore, SDNN represents global HRV. For Gaussian distributions, SDNN estimates that approximately $68 \%$ of the R-R intervals are within \pm 1 SD, $95 \%$ are within \pm 2 SD, and $99 \%$ of the data are within \pm 3 standard deviations. For instance, if the veterinarian performs a 5 min ECG recording and calculates the SDNN, it will reflect the activity of all the regulatory components that act on this time scale (that is, $5 \mathrm{~min}$ ). On the other hand, if the recording has a $>24 \mathrm{~h}$ period (in a Holter recording), the SDNN reflects all the regulatory components that act within a $24 \mathrm{~h}$ period, including circadian mechanisms (Task Force of the European Society of Cardiology, 1996; Rajendra Acharya et al., 2006; Shaffer \& Ginsberg, 2017). For this reason, because different regulatory mechanisms present distinct periodic oscillations, recordings obtained from different time scales should not be compared for SDNN determination (Task Force of the European Society of Cardiology, 1996). For instance, Alfonso et al. (2020) and Baisan et al. (2020) performed SDNN analysis in dogs using 5 min recordings, and found similar results. On the other hand, Bogucki \& Noszczyk-Nowak (2017) used three-hour ECG recordings, while Pirintr et al. (2017) recorded for 14 hours, Hezzell et al. (2018) used 30 min, and Gianfranchesco Filippi et al. (2019) performed Holter recordings of $24 \mathrm{~h}$, and all these studies came across very different results. These differences may not only be ascribed to different time recordings, but also to other factors such as time of the day, animal stress during recordings, and animal size. Spier \& Meurs (2004) evaluated SDNN in boxers with arrhythmogenic right ventricular cardiomyopathy (ARVC) and observed that, in dogs affected by this disease, the SDNN values were reduced when compared to healthy dogs, especially those that developed chronic heart failure (CHF). These data indicate that neurohumoral activation in pathological states, especially ARVC and CHF, may lead to reduced HRV. Bogucki \& Noszczyk-Nowak (2017) evaluated the SDNN of healthy dogs in comparison to those bearing sick-sinus syndrome (SSS) or chronic mitral valve disease (CMVD), and found that healthy animals presented lower SDNN values compared to SSS animals, an effect likely caused by the characteristic increased R-R interval observed in SSS. On the other hand, healthy animals presented higher SDNN values than the CMVD group, and this effect was possibly 
observed by the neurohumoral activation that follows the development of CMVD, leading to a predominance of sympathetic over parasympathetic modulation of the heart (Fujii \& Wakao, 2003). These observations are summarized in Table 1.

Table 1. Summary results of selected studies from the literature, depicting the recording length for data acquisition and the SDNN values for healthy animals or those presenting pathophysiological conditions.

\begin{tabular}{|c|c|c|c|c|}
\hline Study & Species & $\begin{array}{l}\text { Recording } \\
\text { length }\end{array}$ & Healthy & Pathophysiological conditions \\
\hline Alfonso et al. (2020) & Canine & $5 \mathrm{~min}$ & $58.22 \pm 44.46 \mathrm{~ms}$ & CKD4: $29.38 \pm 22.15 \mathrm{~ms}$ \\
\hline Baisan et al. (2020) & Canine & $5 \mathrm{~min}$ & $\begin{array}{l}61.9 \text { ms (median), } \\
\text { 60-77.1 ms (95\% CI) }\end{array}$ & - \\
\hline Bogucki \& Noszczyk-Nowak (2017) & Canine & $3 \mathrm{~h}$ & $208.88 \pm 77.1 \mathrm{~ms}$ & SSS: 208.86 $\pm 77.1 \mathrm{~ms}, \mathrm{CMVD}: 378.16 \pm 40.43 \mathrm{~ms}$ \\
\hline Calvert \& Wall (2001) & Canine & $24 \mathrm{~h}$ & $331 \pm 87 \mathrm{~ms}$ & mDCM: $314 \pm 56$ ms, sDCM: $272 \pm 68$ ms \\
\hline Gianfranchesco Filippi et al. (2019) & Canine & $24 \mathrm{~h}$ & $268 \pm 74.6 \mathrm{~ms}$ & CME: $83 \pm 65 \mathrm{~ms}$ \\
\hline Hezzell et al. (2018) & Canine & $30 \mathrm{~min}$ & $\begin{array}{l}\text { 143.8 ms (median), } \\
\text { 84.8-250.5 ms (range) }\end{array}$ & $\begin{array}{l}\text { ART: } 91.2 \text { ms (median), 83.3- } 119.4 \text { ms (range); NEO: } 193.1 \\
\text { ms (median), 70.9-344.2 ms (range) }\end{array}$ \\
\hline Pirintr et al. (2017) & Canine & $14 \mathrm{~h}$ & $150.3 \pm 10.9 \mathrm{~ms}$ & MMVD: $117.8 \pm 9 \mathrm{~ms}$ \\
\hline Spier \& Meurs (2004) & Canine & $24 \mathrm{~h}$ & $293 \pm 122 \mathrm{~ms}$ & ARVC: $378 \pm 73 \mathrm{~ms}$, ARVC-CHF: $152 \pm 46 \mathrm{~ms}$ \\
\hline
\end{tabular}

$\mathrm{Cl}$, confidende interval; ms, millisecons.

b) Standard deviation of the average N consecutive R-R intervals (SDANN). In this technique, a long-term ECG recording is performed and standard deviation from the R-R intervals for every five-minute segment is obtained. Ultimately, the average of the standard deviations is calculated for the entire recording. Since it is a standard deviation, its value is usually smaller than the average R-R interval, and this index represents the estimate of change in HR due to cycles longer than 5 min (Task Force of the European Society of Cardiology, 1996; Shaffer \& Ginsberg, 2017). As observed for SDNN, SDANN is also an index of global HRV; hence, its values may be affected by the length of the ECG recording and by the longest and shortest R-R intervals. SDANN may also vary depending on the duration of data acquisition (Bogucki \& Noszczyk-Nowak, 2017; Pirintr et al., 2017; Gianfranchesco Filippi et al., 2019). Bogucki \& Noszczyk-Nowak (2017) observed that healthy dogs presented lower SDANN values than animals with SSS, but higher than dogs presenting CMVD. The main SDANN results of the above-mentioned studies are summarized in Table 2.

Table 2. Summary results of selected studies from the literature, depicting the recording length for data acquisition and the SDANN values for healthy animals or those presenting pathophysiological conditions.

\begin{tabular}{llccl}
\hline \multicolumn{1}{c}{ Study } & Species & $\begin{array}{c}\text { Recording } \\
\text { length }\end{array}$ & Healthy & Pathophysiological conditions \\
\hline Bogucki \& Noszczyk-Nowak (2017) & Canine & $3 \mathrm{~h}$ & $70.75 \pm 30.9 \mathrm{~ms}$ & SSS: 125.5 $\pm 58.69 \mathrm{~ms}, \mathrm{CMVD}: 54.3 \pm 25.7 \mathrm{~ms}$ \\
Gianfranchesco Filippi et al. (2019) & Canine & $24 \mathrm{~h}$ & $168.3 \pm 39.14 \mathrm{~ms}$ & CME: $56.05 \pm 37.3 \mathrm{~ms}$ \\
Pirintr et al. (2017) & Canine & $14 \mathrm{~h}$ & $76.7 \pm 12.6 \mathrm{~ms}$ & MMVD: $57.6 \pm 7.9 \mathrm{~ms}$ \\
Spier \& Meurs (2004) & Canine & $24 \mathrm{~h}$ & $172 \pm 46 \mathrm{~ms}$ & ARVC: $176 \pm 35 \mathrm{~ms}$, ARVC-CHF: $82 \pm 21 \mathrm{~ms}$ \\
\hline
\end{tabular}

SSS, sick sinus syndrome; CMVD, chronic mitral valve disease; CKD4, chronic kidney disease stage 4; MMVD, myxomatous mitral valve disease; ms, milliseconds; CME, chronic monocytic ehrlichiosis; ARVC, arrhythmogenic right ventricular cardiomyopathy; CHF, chronic heart failure. Data are presented as mean \pm standard deviation, unless stated otherwise.

c) Average standard deviation of $\boldsymbol{N} \boldsymbol{R}-\boldsymbol{R}$ intervals (SDNNidx). In this analysis, the standard deviation of the N R-R intervals is calculated for every 5 min segment, and the average is computed for the whole recording (Task Force of the European Society of Cardiology, 1996; Shaffer \& Ginsberg, 2017). In other words, it is performed by calculating the SDNN for every 5 min segment and then normalizing the sum of them by the number of 5 min segments contained in the entire recording. If SDNNidx is calculated over a $24 \mathrm{~h}$ period, it will result in 
288 five-minute segments. Therefore, this index calculates HRV due to cycles shorter than 5 min (Task Force of the European Society of Cardiology, 1996; Shaffer \& Ginsberg, 2017). Since it is normalized by the length of the raw recording, its value is less variable than, for example, SDNN; for a $3 \mathrm{~h}$ recording, Bogucki \& Noszczyk-Nowak (2017) found the value to be 190.75 $\pm 76.12 \mathrm{~ms}$, while Pirintr et al. (2017) observed 128.7 $\pm 9.4 \mathrm{~ms}$ for a $14 \mathrm{~h}$ recording, and Gianfranchesco Gianfranchesco Filippi et al. (2019) obtained 216.9 \pm 74.28 ms in a 24 hourslong recording. Bogucki \& Noszczyk-Nowak (2017) also observed that clinically normal dogs exhibited lower SDNNidx values (190.75 $\pm 76.12 \mathrm{~ms}$ ) when compared to dogs presenting SSS (341.4 $\pm 56.69 \mathrm{~ms})$, but higher than those presenting CMVD (117.21 $\pm 70.5 \mathrm{~ms})$. It is important to note that SDNNidx represents sympathetic and parasympathetic regulation of HRV (Shaffer \& Ginsberg, 2017). The results are summarized in Table 3.

Table 3. Summary results of selected studies from the literature, depicting the recording length for data acquisition and the SDNNidx values for healthy animals or those presenting pathophysiological conditions.

\begin{tabular}{|c|c|c|c|c|}
\hline Study & Species & $\begin{array}{l}\text { Recording } \\
\text { length }\end{array}$ & Healthy & Pathophysiological conditions \\
\hline Bogucki \& Noszczyk-Nowak (2017) & Canine & $3 \mathrm{~h}$ & $190.75 \pm 76.12 \mathrm{~ms}$ & SSS: $341.4 \pm 56.69 \mathrm{~ms}, \mathrm{CMVD}: 117.21 \pm 70.5 \mathrm{~ms}$ \\
\hline Gianfranchesco Filippi et al. (2019) & Canine & $24 \mathrm{~h}$ & $216.9 \pm 74.28 \mathrm{~ms}$ & CME: $57.55 \pm 55.9 \mathrm{~ms}$ \\
\hline Pirintr et al. (2017) & Canine & $14 \mathrm{~h}$ & $128.7 \pm 9.4 \mathrm{~ms}$ & MMVD: $106.6 \pm 10.2 \mathrm{~ms}$ \\
\hline
\end{tabular}

SSS, sick sinus syndrome; CMVD, chronic mitral valve disease; MMVD, myxomatous mitral valve disease; CME, chronic monocytic ehrlichiosis. Data are presented as mean \pm standard deviation, unless stated otherwise

d) Square root of the mean squared differences of successive Nintervals (RMSSD). Although it has a complex name, the idea behind it is very simple, especially if the reader is familiar with statistics. First, every single R-R interval is measured to form a time series, and another table is derived to enlist the time difference between every two consecutive R-R intervals, expressing those values in ms. Each of these differences is squared, summed, and then divided by the number of R-R intervals to obtain a mean value of the squared differences. The obtained value thus far represents a type of variance (beat-to-beat variance). Finally, a squared root is obtained from the squared mean, resulting in the RMSSD value, which represents a beat-to-beat standard deviation. This measurement can be obtained from short recordings, such as 5 min segments (Task Force of the European Society of Cardiology, 1996). RMSSD is strongly correlated to the High Frequency (HF) power of the Fast Fourier Transform (FFT-seebelow) and, therefore, to parasympathetic modulation (Shaffer \& Ginsberg, 2017). Bogucki and Noszczyk-Nowak (2017) computed values of RMSSD for clinically healthy dogs and observed that these values were significantly higher than those observed in dogs with SSS and those presenting with CMVD. The results of studies from the literature are summarized in Table 4.

Table 4. Summary results of selected studies from the literature, depicting the recording length for data acquisition and the RMSSD values for healthy animals or those presenting pathophysiological conditions.

\begin{tabular}{|c|c|c|c|c|}
\hline Study & Species & $\begin{array}{c}\text { Recording } \\
\text { length }\end{array}$ & Healthy & Pathophysiological conditions \\
\hline Alfonso et al. (2020) & Canine & $5 \mathrm{~min}$ & $74.05 \pm 52.86 \mathrm{~ms}$ & CDK4: $40.63 \pm 24.77 \mathrm{~ms}$ \\
\hline Baisan et al. (2020) & Canine & $5 \min$ & $\begin{array}{c}56.6 \mathrm{~ms} \text { (median), } \\
69.9-102.5 \mathrm{~ms}(95 \% \mathrm{CI})\end{array}$ & - \\
\hline Bogucki \& Noszczyk-Nowak (2017) & Canine & $3 \mathrm{~h}$ & $259 \pm 120.17 \mathrm{~ms}$ & SSS: $54.1 \pm 87.55 \mathrm{~ms}, \mathrm{CMVD}: 172.66 \pm 116.68 \mathrm{~ms}$ \\
\hline Calvert \& Wall (2001) & Canine & $24 \mathrm{~h}$ & $325 \pm 118 \mathrm{~ms}$ & mDCM: $295 \pm 72$ ms, sDCM: $245 \pm 101 \mathrm{~ms}$ \\
\hline Gianfranchesco Filippi et al. (2019) & Canine & $24 \mathrm{~h}$ & $146.9 \pm 45.5 \mathrm{~ms}$ & CME: $55.2 \pm 50 \mathrm{~ms}$ \\
\hline Hezzell et al. (2018) & Canine & $30 \mathrm{~min}$ & $\begin{array}{l}\text { 166.8 ms (median), } \\
\text { 52.9-198.9 ms (range) }\end{array}$ & $\begin{array}{l}\text { ART: } 64.5 \text { ms (median), 58.7-97.2 ms (range); } \\
\text { NEO: } 277.1 \text { (median), 58.2-414.7 (range) }\end{array}$ \\
\hline Pirintr et al. (2017) & Canine & $14 \mathrm{~h}$ & $133.1 \pm 9.4 \mathrm{~ms}$ & MMVD: $112.8 \pm 10.3 \mathrm{~ms}$ \\
\hline
\end{tabular}

SSS, sick sinus syndrome; CMVD, chronic mitral valve disease; CKD4, chronic kidney disease stage 4; MMVD, myxomatous mitral valve disease; ART, arthritis; NEO, neoplasia; CME, chronic monocytic ehrlichiosis; mDCM, mild/moderate dilated cardiomyopathy; SDCM, severe dilated cardiomyopathy; ms, milliseconds; Cl, confidence interval. Data are presented as mean \pm standard deviation, unless stated otherwise. 
e) Percentage of the number of the $N$ adjacent $R-R$ interval differences greater than $50 \mathrm{~ms}$ (pNN50): In this method, every R-R interval is compared to the adjacent one, and the difference between them is computed. Then, the number of comparisons of adjacent intervals with differences $>50 \mathrm{~ms}$ is observed (NN50). This number is then divided by the total number of comparisons to obtain a percentage (Task Force of the European Society of Cardiology, 1996). Like RMSSD, pNN50 represents an estimate of the high-frequency variations in HR and, therefore, may be related to parasympathetic regulation of the heart. In addition, as expected, RMSSD and pNN50 present a strong mutual correlation (pNN50 also represents the parasympathetic regulation of the heart). Baisan et al. (2020) found a median value of $27.5 \%$, with a $95 \%$ of confidence interval (CI) of $29.2 \%$ - $41.7 \%$, for healthy dogs. Moreover, Bogucki and Noszczyk-Nowak (2017) measured pNN50 values for healthy dogs (71.84 $\pm 13.69 \%)$ and compared them to those found in dogs with SSS (86.68 $\pm 8.12 \%)$ and dogs with CMVD (51.56 $\pm 32.5 \%)$, indicating that the parasympathetic activity to the heart is lower in healthy animals than in dogs with SSS, but higher than that in animals with CMVD. See Table 5 for a comparison of pNN50 values found in studies from the literature.

Table 5. Summary results of selected studies from the literature, depicting the recording length for data acquisition and the pNN50 values for healthy animals or those presenting pathophysiological conditions.

\begin{tabular}{lcccc}
\hline \multicolumn{1}{c}{ Study } & Species & $\begin{array}{c}\text { Recording } \\
\text { length }\end{array}$ & Healthy & Pathophysiological conditions \\
\hline Baisan et al. (2020) & Canine & 5 min & $27.5 \%$ (median), $29.2-41.7 \%$ (95\% CI) & - \\
Bogucki \& Noszczyk-Nowak (2017) & Canine & $3 \mathrm{~h}$ & $71.84 \pm 13.69 \%$ & SSS: $86.68 \pm 8.12 \%$, CMVD: $51.56 \pm 32.5 \%$ \\
Calvert \& Wall (2001) & Canine & $24 \mathrm{~h}$ & $56 \pm 10 \%$ & mDCM: $52 \pm 9 \%$, sDCM: $48 \pm 11 \%$ \\
Gianfranchesco Filippi et al. (2019) & Canine & $24 \mathrm{~h}$ & $55.87 \pm 12.8 \%$ & CME: $14.56 \pm 20.1 \%$ \\
Pirintr et al. (2017) & Canine & $14 \mathrm{~h}$ & $46.9 \pm 5.1 \%$ & MMVD: $33.6 \pm 4.0 \%$ \\
\hline
\end{tabular}

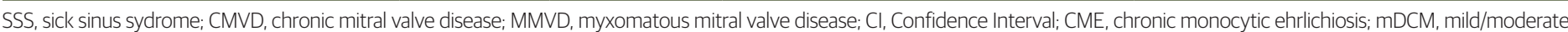
dilated cardiomyopathy; sDCM, severe cardiomyopathy. Data are presented as mean \pm standard deviation, unless stated otherwise.

In addition to statistical methods, time domain analysis also includes geometrical methods. This analysis can be achieved by converting the time series into a graph that contains geometrical attributes used to represent HRV (Task Force of the European Society of Cardiology, 1996; Shaffer and Ginsberg). There are two main methods used in veterinary medicine: the triangular index (HTI) and the Lorenz plot (also known as Poncairé plot).

f) Triangular interpolation of the NN interval histogram (TINN): To analyze the HTI, a density plot should be constructed. It is a graph that presents at the x-axis all the possible values for the R-R interval in a given time series, and at the $y$ axis, the number of times each value of the R-R interval occurs. Observing the density graph as a whole, it is possible to notice that this histogram usually forms a triangular-shaped figure, where the width of the base of the formed triangle (on the $x$-axis) represents the variability of the R-R intervals, and the height of the triangle represents the number of times the most frequent $\mathrm{R}-\mathrm{R}$ interval occurred (modal frequency, see Figure 1). TINN corresponds to the baseline width of the histogram (Task Force of the European Society of Cardiology, 1996; Shaffer \& Ginsberg, 2017). It correlates well with SDNN; therefore, TINN also represents the total power of HRV (Task Force of the European Society of Cardiology, 1996; Rajendra Acharya et al., 2006; Shaffer \& Ginsberg, 2017). It is sensitive to artefacts or arrhythmias (such as SDNN and RMSSD), as these events are integrated into the triangular graph, requiring further processing to exclude them. Contamination by only two events in a five-minute recording can distort the results (Shaffer \& Ginsberg, 2017). The summarized results from selected studies are shown in Table 6.

g) Lorenz Plots: Also called Poincaré Plots, the theoretical basis for this analysis is found in the analysis of nonlinear systems (Rajendra Acharya et al., 2006). In practical terms, this analysis is achieved by constructing a plot from a time series, where the $\mathrm{x}$-axis presents every R-R interval and the $y$-axis contains the subsequent $\mathrm{R}$-R interval to that plotted on 
Table 6. Summary results of selected studies from the literature, depicting the recording length for data acquisition and the HTI values for healthy animals or those presenting pathophysiological conditions.

\begin{tabular}{|c|c|c|c|c|}
\hline Study & Species & $\begin{array}{l}\text { Recording } \\
\text { length }\end{array}$ & Healthy & Pathophysiological conditions \\
\hline Hezzell et al. (2018) & Canine & $30 \mathrm{~min}$ & $\begin{array}{l}269.9 \text { ms (median); } \\
153.6 \text { - } 437.5 \text { ms (range). }\end{array}$ & $\begin{array}{l}\text { ART: } 332.1 \text { ms (median), } 140.7 \text { - } 375.0 \text { ms (range); } \\
\text { NEO: } 242.2 \text { ms (median), } 175.8 \text { - } 384.8 \text { ms (range) }\end{array}$ \\
\hline Gianfranchesco Filippi et al. (2019) & Canine & 24 hours & $267.37 \pm 113.38 \mathrm{~ms}$ & CME: $648.88 \pm 238.97 \mathrm{~ms}$ \\
\hline
\end{tabular}

ART, arthritis; NEO, neoplasia; CME, chronic monocytic ehrlichiosis; ms, milliseconds. Data are presented as mean \pm standard deviation, unless stated otherwise.
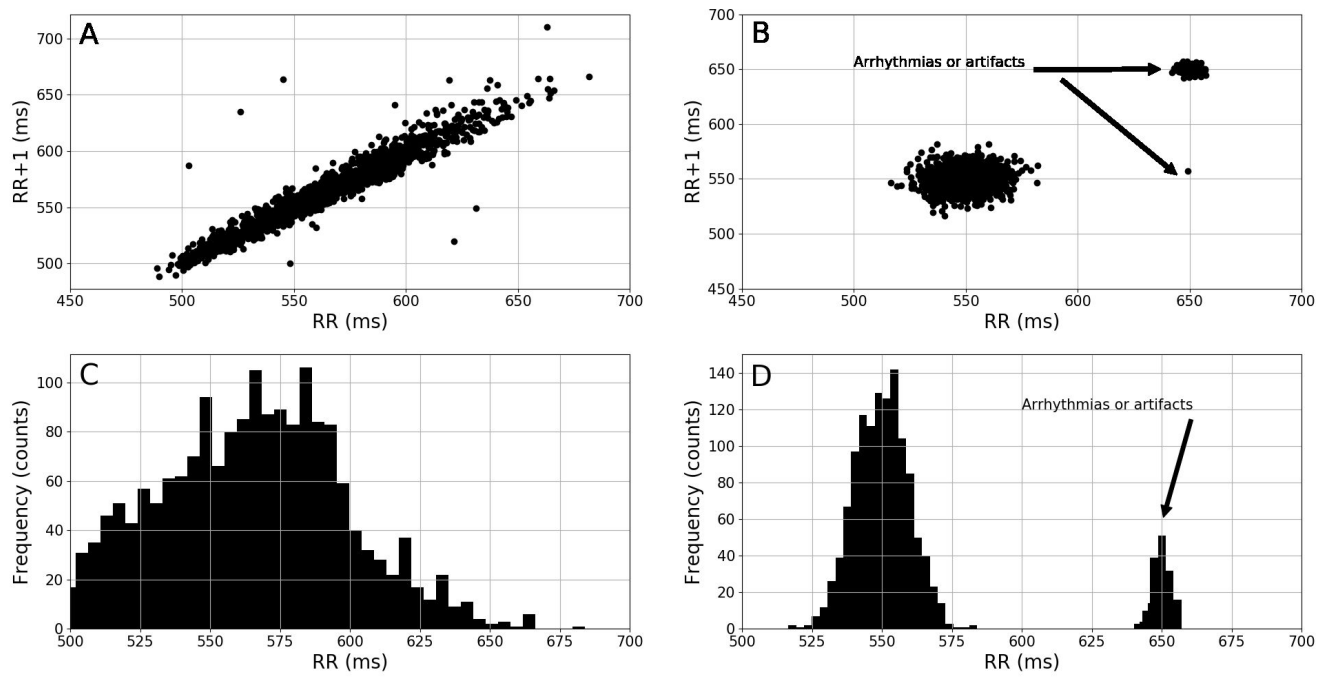

Figure 2. (A) Lorenz plot of a dog with a good HRV (comet); (B) Lorenz plot of a dog with a poor HRV (disk). It is also possible to observe that artifacts or arrhythmias are clustered in a different region of the graph, making it possible to identify these events; (C) Density histogram of the same dog as seen in A; (D) Density histogram of the same dog as seen in B, where it is possible to observe that arrhythmias or artifacts present different modal frequencies.

the x-axis. In this way, every interval on the x-axis is related to its subsequent interval on the $y$-axis. The output of this procedure is a graph where the plotted dots form a figure related to the R-R variability: in an animal with good HRV, the output figure will be wide and resembling a "comet" with the head toward the origin of the graph. On the other hand, in an animal with poor $\mathrm{HRV}$, the graph will be compact and exhibit an ellipsoid form, resembling a "rocket" or a "disk" (Figure 2 - Shaffer \& Ginsberg, 2017). In addition, time series that contain artefacts will result in graphs with more than one group of dots, indicating a poor quality recording or the presence of arrhythmias. Lorenz plots also provide quantitative information by calculating two standard deviations: SD2, which represents the standard deviation of every dot in the graph from the line $y=x$ (bissetrix of the graph), and SD1, which calculates the standard deviation of every $R_{i}-R_{i+1}$ interval from the line $y=-x+2 R-R_{m}$ (this line forms $90^{\circ}$ with the SD1 line). The SD1/SD2 ratio is a measure of how large the fast regulatory mechanisms are in relation to slow regulatory mechanisms. SD2 of the figure is related to the overall long-term variability (sympathetic and parasympathetic - like SDNN and SDANN), while SD1 of the figure indicates short-term variability (mostly parasympathetic, such as RMSSD and PNN50; Rajendra Acharya et al., 2006; Blake et al., 2018). Blake et al. (2018) observed SD1 mean value of $1967 \mathrm{~ms}$ (within a range of 1511 - $1884 \mathrm{~ms}$ ), SD2 mean value of $2630 \mathrm{~ms}$ (range 2505 - $2755 \mathrm{~ms}$ ), and SD1/SD2 ratio of $0.69 \mathrm{~ms}$ (median) for a $0.31-0.80 \mathrm{~ms}$ range. There are very few clinical studies in the literature regarding Poncairé plot analysis in dogs and cats, allowing comparisons among them. Figure 2 illustrates examples from two dogs (one with a good HRV and one with a poor HRV), showing density histograms and Lorenz plots. 

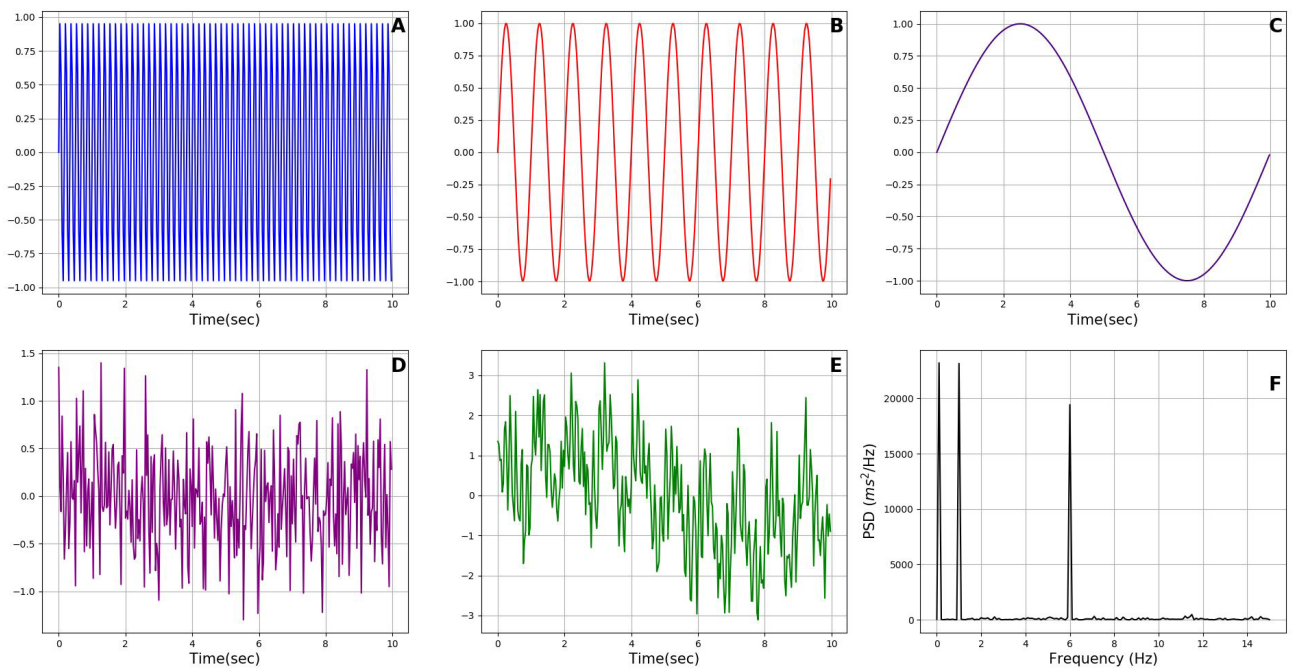

Figure 3. (A) Representation of an undulatory signal with a frequency of $6.0 \mathrm{~Hz}$; (B) Undulatory signal with a frequency of $1.0 \mathrm{~Hz}(\mathbf{C})$ Undulatory signal with a frequency of $0.1 \mathrm{~Hz}$; (D) Signal representing an aperiodic random noise; (E) Summation of the signals presented at panels A, B, C, and D; (F) Graph of power spectrum density decomposing (by FFT algorithm) the signal presented in panel E. Observe the peaks representing each one of the composing frequencies and the aperiodic noise at the baseline.

\section{Frequency domain methods:}

The frequency domain methods are regarded as a set of mathematical algorithms that permit the analysis of undulatory signals according to their composing frequency bands (Altimiras, 1999) and are based on the analysis of periodic fluctuations of HRV from short or long recordings (usually 24h or 5 min; Task Force of the European Society of Cardiology, 1996; Billman, 2011). There are two main classes of frequency domain methods: parametric (autoregressive analysis) and non-parametric (fast Fourier transform). Owing to its simplicity, the most frequently used method is FFT (Altimiras et al., 1994; Altimiras, 1999). Collectively, these techniques are known under the denomination spectral analysis or power spectrum and are applied in the determination of physiological mechanisms implied in HRV. Several physiological rhythms contribute to HRV, such as (from the longest to the shortest period): age-related changes (heart rate tends to decrease with aging process), annual seasonal rhythms (especially important for hibernating or aestivating animals), circadian rhythms (hormonal and autonomic changes during the day), ultradian rhythms (probably related to the activity of suprachiasmatic nuclei and hormonal fluctuations), infradian rhythms (determined by neurohumoral fluctuations and mainly determined by autonomic innervation to the sinoatrial node), and beat-to-beat rhythms (associated with cardiovascular neural reflexes) (Altimiras, 1999). All these regulatory components are entrained in HRV fluctuations, giving rise to a complex undulatory behavior that, in turn, can be decomposed into simpler undulatory components grouped in frequency bands (Altimiras et al., 1994; Task Force of the European Society of Cardiology, 1996; Altimiras, 1999; Rajendra Acharya et al., 2006; Billman, 2011; Shaffer \& Ginsberg, 2017). Most frequently, spectral analysis is applied to investigate beat-to-beat rhythms (regarded as short-term HRV; STHRV). A good and simple explanation of how spectral analysis works can be found in Figure 3, where we present three sinusoidal waves (panel $A=6 \mathrm{~Hz}$, panel $\mathrm{B}=1 \mathrm{~Hz}$, and panel $\mathrm{C}=0.1 \mathrm{~Hz}$ ) and one random and aperiodic signal (panel D). These four signals together form a complex waveform, that can be observed in panel $\mathrm{E}$ (a wave resembling the periodogram usually found from ECG recordings). The application of the FFT algorithm (see below) is able to decompose the complex signal from panel $\mathrm{E}$. It is possible to identify three peaks in panel $\mathrm{F}$, each one corresponding to composing frequencies found in panels $\mathrm{A}(6 \mathrm{~Hz}), \mathrm{B}(1 \mathrm{~Hz})$, and $\mathrm{C}$ $(0.1 \mathrm{~Hz}$ ). The aperiodic noise (panel D) added to the signal (panel E) could be observed at the baseline of panel $F$. Therefore, by spectral analysis, we could decompose a complex signal and identify the composing frequencies. 
Although spectral analysis methods are not mathematically complex, they are beyond the scope of this manuscript to discuss in mathematical terms. It is recommended, to the readers interested in the processing aspects of frequency domain methods, to read the manuscripts by Altimiras et al. (1994) and Altimiras (1999) and Rajendra Acharya et al. (2006). A brief outline is presented here in short: the ECG recording must be digitized (most veterinary ECG recording systems are digital nowadays) and the R-R intervals should be accurately detected, resulting in an interval tachogram, and all the artifacts should be removed. As a standard quality rule, if the artifacts represent more than $5 \%$ of the entire recording, the data series are not suitable for spectral analysis. Then, FFT or auto-regressive method (AR) can be applied (Altimiras et al., 1994; Altimiras, 1999). The graphic representation of the R-R variability along the time results is the so-called "periodogram," where it is easy to observe the periodic fluctuations in HRV. The instantaneous heart rate could also be used, resulting in a "tachogram." The FFT method assumes that every auditory signal is a combination of sinusoidal waves with different frequencies that can be decomposed and measured. However, FFT requires the data series to be stationary and infinite, and the biological signal is not. Therefore, a tapering window must be applied to avoid spectral leakage (a truncation effect in the data series that occurs when the data is not in phase with itself, and tends to mask weak signals). This means that the overall recording will be divided into short enough windows (segments) where the contained signal is stationary; for example, $2^{8}$ data points each and the Fourier transform will be applied to each window. As a result of windowing a non-stationary signal, disruption is expected at the boundaries; this means that the ending of one window will not match the ending of the others, and a discontinuity in the data will be observed. Therefore, using a window function with tapered endings provides a good solution (the differences are minimized at the edges of the window, smoothing truncation errors), the most frequently used tapering windows are Hamming and Hanning windows (both presenting high amplitude at the center and low amplitude-tapered-at the edges). Gaussian windows could be used as well, and in this case, the algorithm is called the Gabor transform. However, because the windowing process disrupts the interval boundaries, it is important to overlap the intervals (usually in $50 \%$ of its length) (Wallisch et al., 2009). The resulting periodograms are averaged, and the area under the curve within specific frequency ranges is measured, resulting in a good estimation of the power spectrum of each frequency band. In the AR method, the data are fitted to an a priori defined mathematical model for HRV, which assumes the data series to be both stationery and infinite (Altimiras, 1999; Billman, 2011); therefore, a windowing process is not required.

The main advantage of the Auto-Regressive (AR) method is its better resolution compared to the FFT method (Altimiras, 1999). As for FFT, the spectral power of a given frequency in AR is obtained by determining the area under the curve within a specific frequency band (Billman, 2011). The spectral components are divided into frequency ranges: ultra-low frequency (ULF), very-low frequency (VLF), low frequency (LF), and high frequency (HF) (Figure 4). Each of these
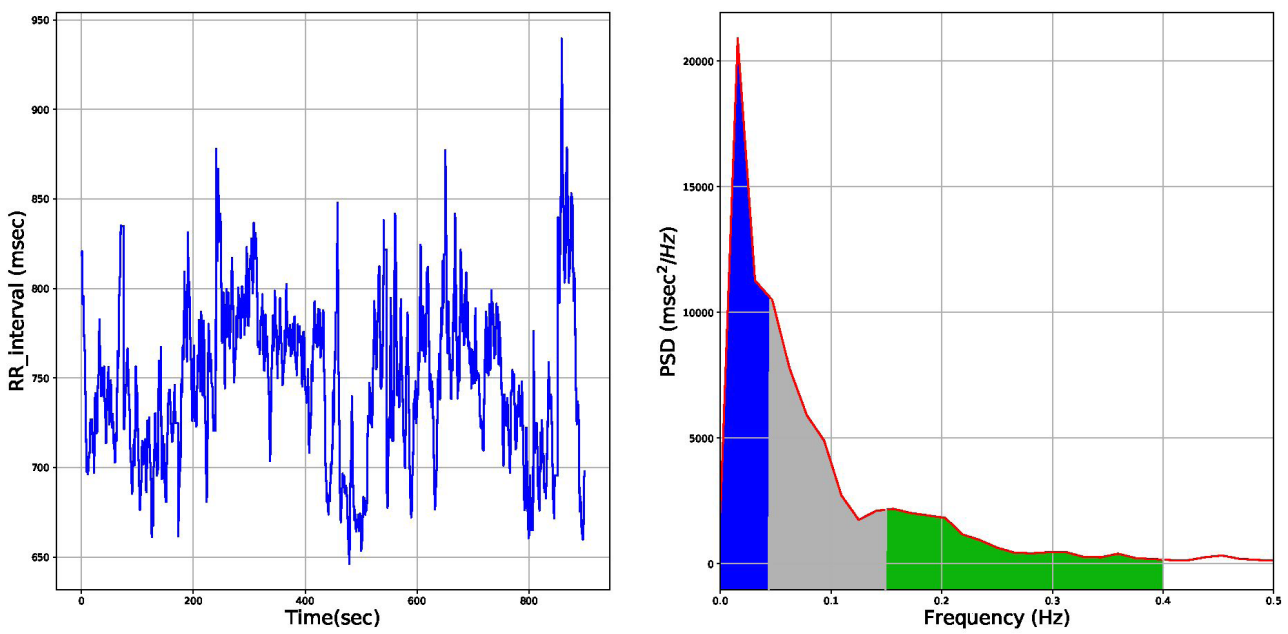

Figure 4. (A) Periodogram of a 15-minute ECG recording, illustrating the HRV over time; (B) Power spectral density graph obtained by FFT from the recording shown in panel A, indicating the areas corresponding to each frequency band. (VLF: $0.003-0.04$ Hz, LF: 0.04 - 0.15 Hz, HF: 0.15 - 0.4 Hz.) 
spectral components is influenced by a set of physiological mechanisms that contribute to HRV within different time scales. Usually, the spectral components are expressed as $\mathrm{ms}^{2}$, from direct measurement of the area under the curve of the considered spectral range; however, since each individual animal has, for example, its own level of sympathetic and parasympathetic activity, it is difficult to compare raw measurements of spectral power among different animals., This is true even for the same animal, if one considers comparing the before and after of a pharmacological treatment. For practical purposes, if one wants to compare LF spectral components from different animals, it is important to normalize the measured $\mathrm{LF}\left(\right.$ in $\mathrm{ms}^{2}$ ) in relation to the total spectral power (that is, the sum of LF and HF or the total power minus the VLF component, and therefore, representing the percentage of sympatho-vagal balance attributed to the specific spectral component: $\mathrm{LF}$ or $\mathrm{HF}$ ). This procedure outputs a variable that lacks dimensions and is often regarded as normalized units (n.u.). In addition, the ratio between LF and HF (LF:HF) yields an important and often used estimation of sympatho-vagal balance and is expressed as absolute units (a.u., although sometimes authors express this number as a percentage). The frequency bands usually measured by frequency domain methods are as follows:

a) Ultra-Low Frequency(ULF): It is still unclear what mechanisms contribute to this frequency band, even when considering autonomic components. It is possible that body temperature and the renin-angiotensin system are involved in this oscillation (Shaffer \& Ginsberg, 2017). The ULF frequency band can only be measured from an atleast 24h-long recording (Task Force of the European Society of Cardiology, 1996; Shaffer \& Ginsberg, 2017) and the ULF spectral component ranges from $\mathbf{0}$ to $\mathbf{0 . 0 0 3} \mathbf{~ H z}$ in dogs (Oliveira et al., 2014). Calvert \& Wall (2001) evaluated the ULF in Doberman Pinscher dogs and observed that healthy dogs presented ULF values $\left(55258 \pm 33422 \mathrm{~ms}^{2}\right)$ that did not differ from those presenting mild $\left(45495 \pm 21894 \mathrm{~ms}^{2}\right)$ or severe $\left(39130 \pm 13421 \mathrm{~ms}^{2}\right)$ dilated cardiomyopathy; therefore, this frequency band may not include mechanisms that are activated during cardiovascular pathophysiological states.

b) Very-Low Frequency(VLF): This frequency band appears to be generated by the stimulation of cardiac afferents, thereby, changing the sympathetic and parasympathetic efferent activity. Therefore, the LF frequency component reflects the sympathetic and parasympathetic modulation of HRV and is influenced by baroreceptor mechanisms (Akselrod et al., 1981; Abbott, 2005). It is also possible that thermoregulatory mechanisms, as well as the reninangiotensin-system and endothelin, contribute to this frequency band. The VLF component correlates well with SDNNidx, and the minimum recording length for VLF determination is 5 min (Task Force of the European Society of Cardiology, 1996; Abbott, 2005; Shaffer \& Ginsberg, 2017). The VLF range in cats has been reported to consitute all spectral components below $0.04 \mathrm{~Hz}$ (Abbott, 2005). For dogs, the VLF spectral component ranges from $\mathbf{0 . 0 0 3}$ to $0.04 \mathbf{~ H z}$ (Oliveira et al., 2014). Since autonomic modulation does not seem to be included in this frequency band, veterinarians are not very interested in it; therefore, very few studies have addressed this component. Table 7 shows the selected VLF results from the literature on healthy and diseased animals.

Table 7. Summary results of selected studies from the literature, depicting the recording length for data acquisition and the VLF values for healthy animals or those presenting pathophysiological conditions.

\begin{tabular}{|c|c|c|c|c|}
\hline Study & Species & $\begin{array}{l}\text { Recording } \\
\text { length }\end{array}$ & Healthy & Pathophysiological conditions \\
\hline Baisan et al. (2020) & Canine & $5 \min$ & $\begin{array}{c}164 \mathrm{~ms}^{2} \text { (median), } 274 \text { - } 618 \mathrm{~ms}^{2} \\
\text { (95\% CI) }\end{array}$ & - \\
\hline $\begin{array}{l}\text { Bogucki \& Noszczyk- } \\
\text { Nowak (2017) }\end{array}$ & Canine & $3 \mathrm{~h}$ & $984.96 \pm 327.7 \mathrm{~ms}^{2}$ & \\
\hline Calvert \& Wall (2001) & Canine & $24 \mathrm{~h}$ & $14776 \pm 8835 \mathrm{~ms}^{2}$ & mDCM: $14363 \pm 7957 \mathrm{~ms}^{2}, \mathrm{sDCM}: 11874 \pm 4969 \mathrm{~ms}^{2}$ \\
\hline Oliveira et al. (2014) & Canine & $24 \mathrm{~h}$ & $544.5 \pm 369.9 \mathrm{~ms}^{2}$ & MMVD: $873.8 \pm 755.8 \mathrm{~ms}^{2}, \mathrm{MMVD}+\mathrm{HF}: 269.5 \pm 278.6 \mathrm{~ms}^{2}$ \\
\hline
\end{tabular}

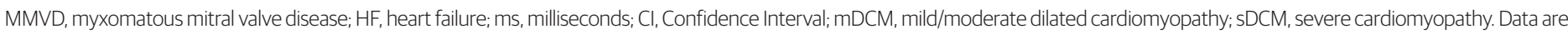
presented as mean \pm standard deviation, unless stated otherwise. 
c) Low-frequency (LF): Both sympathetic and parasympathetic modulation-contribute to this frequency band. However, at rest condition, LF power correlates better with the degree of baroreflex modulation of sympathetic activity (Shaffer \& Ginsberg, 2017), because LF values could be significantly reduced after the i.v. administration of propranolol, revealing the role of sympathetic modulation in LF values (Matsunaga et al., 2001). In cats, LF spectral ranges from 0.04 to $0.15 \mathrm{~Hz}$ (Abbott, 2005). For dogs, the LF spectral component has been noted to range from 0.04 to $0.1 \mathrm{~Hz}$ (Matsunaga et al., 2001) or 0.04 to $0.15 \mathrm{~Hz}$ (Oliveira et al., 2014). Holter recordings from supposed healthy cats in a hospital environment and at home were obtained in order to measure HRV by FFT, and it was observed that there was no significant statistical difference in the LF spectral component between these two housing paradigms (Abbott, 2005). However, when the LF measurement was normalized according to the total power, the difference became evident. Thus, it is clear that environmental factors must be considered when evaluating the results of HRV analysis, as they may affect autonomic efferent activity. Matsunaga et al. (2001) observed a statistical difference in LF values for dogs during the day and night. Therefore, the time of day for LF measurements must also be considered due to the circadian influence on autonomic activity. Baisan et al. (2020) found an LF value of $652 \mathrm{~ms}^{2}$ (median) for healthy dogs and a 95\% CI ranging from 714 to $1,113 \mathrm{~ms}^{2}$. In another study, Bogucki \& Noszczyk-Nowak (2017) observed that healthy dogs presented lower LF values than animals with SSS, but higher than the values observed in dogs presenting chronic mitral valve disease. Similar results were observed in the study conducted by Oliveira et al. (2014), where a significantly reduced LF component was observed in healthy dogs compared to dogs with CMVD and those with heart failure. Taken together, these data indicate that the increase in the LF spectral component of HRV may be induced by the activation of the neurohumoral axis present in CMVD. Regarding dilated cardiomyopathy, Minors \& O'Grady (1997) showed that the LF frequency band does not differ between healthy Doberman Pinschers and those with dilated cardiomyopathy (except when CHF dogs develop the condition). These data are in accordance with a study by Calvert and Wall (2001), where similar results were observed. Some authors advocate that LF is a good sympathetic marker for sympathetic modulation of the heart, while others believe that LF represents baroreceptor modulation of the heart (Piccirillo et al., 2009). The data discussed above are summarized in Table 8.

Table 8. Summary results of selected studies from the literature, depicting the recording length for data acquisition and the $\mathbf{L F}$ values for healthy animals or those presenting pathophysiological conditions.

\begin{tabular}{|c|c|c|c|c|}
\hline Study & Species & $\begin{array}{l}\text { Recording } \\
\text { length }\end{array}$ & Healthy & Pathophysiological conditions \\
\hline Abbott (2005) & Feline & $4 \mathrm{~min}$ & $\begin{aligned} & \text { Home: } 1.37 \mathrm{~ms}^{2} \text { (mean), } 0.31 \text { - } 8.6 \mathrm{~ms}^{2} \text { (range); Hospital: } \\
& 1.92 \mathrm{~ms}^{2} \text { (mean), } 0.36 \text { - } 9.89 \mathrm{~ms}^{2} \text { (range) }\end{aligned}$ & - \\
\hline Alfonso et al. (2020) & Canine & $5 \mathrm{~min}$ & $19.69 \pm 14.49$ n.u. & 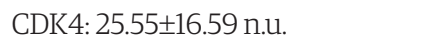 \\
\hline Baisan et al. (2020) & Canine & $5 \min$ & 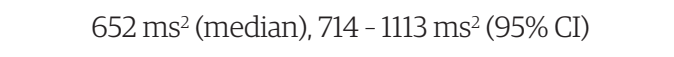 & - \\
\hline $\begin{array}{l}\text { Bogucki \& Noszczyk- } \\
\text { Nowak (2017) }\end{array}$ & Canine & $3 \mathrm{~h}$ & $1501.21 \pm 736.32 \mathrm{~ms}^{2}$ & \\
\hline Calvert \& Wall (2001) & Canine & $24 \mathrm{~h}$ & $21403 \pm 20190 \mathrm{~ms}^{2}$ & $\begin{array}{l}\text { mDCM: } 28879 \pm 20109 \mathrm{~ms}^{2}, \mathrm{sDCM}: \\
18247 \pm 11172 \mathrm{~ms}^{2}\end{array}$ \\
\hline $\begin{array}{l}\text { Matsunaga et al. } \\
\text { (2001) }\end{array}$ & Canine & $6 \mathrm{~h}$ & $330 \pm 150 \mathrm{~ms}^{2}$ & - \\
\hline $\begin{array}{l}\text { Minors \& O'Grady } \\
\text { (1997) }\end{array}$ & Canine & $20 \mathrm{~min}$ & $122.5 \pm 46.18 \mathrm{~ms}^{2}$ & $\begin{array}{l}\text { oDCM: } 90.4 \pm 29.4 \mathrm{~ms}^{2}, \mathrm{DCM}-\mathrm{CHF}: \\
\text { 50.0 } \pm 36.1 \mathrm{~ms}^{2}\end{array}$ \\
\hline Oliveira et al. (2014) & Canine & $24 \mathrm{~h}$ & $1026.2 \pm 788.7 \mathrm{~ms}^{2}$ & $\begin{array}{l}\text { MMVD: } 1082.5 \pm 831.7 \mathrm{~ms}^{2} \\
\text { MMVD+HF: } 617.5 \pm 472.4 \mathrm{~ms}^{2}\end{array}$ \\
\hline Pirintr et al. (2017) & Canine & $14 \mathrm{~h}$ & $2356.5 \pm 197.4 \mathrm{~ms}^{2}$ & MMVD: $2447.7 \pm 397.7 \mathrm{~ms}^{2}$ \\
\hline
\end{tabular}

MMVD, myxomatous mitral valve disease; DCM-CHF, Dilated cardiomyopathy - congestive heart failure stage; mDCM, mild/moderate dilated cardiomyopathy; sDCM, severe cardiomyopathy; oDCM, occult dilated cardiomyopathy; n.u., normalized units. Data are presented as mean \pm standard deviation, unless stated otherwise. 
d) $\quad \boldsymbol{H} \boldsymbol{F}$ (High-Frequency): This frequency band represents the degree of parasympathetic modulation originated by the respiratory activity (therefore, this band is often called "respiratory band"). According to Akselrod et al. (1981), the HF frequency component of HRV reflects the parasympathetic modulation of the heart. It is important to point out that HF measurement does not reflect vagal tone, but simply the parasympathetic modulation. If one wants to estimate the vagal tone of the heart, one should measure the lnHF (natural logarithm of HF; Task Force of the European Society of Cardiology, 1996; Shaffer \& Ginsberg, 2017). The HF spectral components for cats are measured from 0.15 to $0.7 \mathbf{~ H z}$ (Abbott, 2005). The HF spectral component for dogs has been found to range from $\mathbf{0 . 1} \mathbf{~ t o} \mathbf{0 . 6} \mathbf{~ H z}$ (Matsunaga et al., 2001) or 0.15 to $\mathbf{0 . 4 ~ H z}$ (Oliveira et al., 2014). Abbott (2005) found that the raw values of $\mathrm{HF}$ for healthy cats were (in average) $1.16 \mathrm{~ms}^{2}$ for hospitalized and $2.19 \mathrm{~ms}^{2}$ for domiciliated animals, while the normalized values for this premise were $39.2 \pm 0.19$ n.u. and $60.1 \pm 0.19$ n.u., respectively. In a study conducted in healthy dogs, Baisan et al. (2020) found a median HF value of $635 \mathrm{~ms}^{2}$ and a 95\% CI ranging from 932 to $2385 \mathrm{~ms}^{2}$. Matsunaga et al. (2001) observed that the values for canine HF were significantly different during the day $\left(5868 \pm 1714 \mathrm{~ms}^{2}\right.$ or $67.2 \pm 10$ n.u.) from the results obtained during the night $(16650 \pm 5242$ $\mathrm{ms}^{2}$ or $78.4 \pm 5.4$ n.u.). In the same study (Matsunaga et al., 2001), the authors showed that i.v. administration of atropine significantly reduced both $\mathrm{HF}$ and LF spectral components, indicating the role of parasympathetic modulation in both LF and HF bands. Moreover, Bogucki \& Noszczyk-Nowak (2017) observed that healthy dogs presented lower values of $\mathrm{HF}$ in comparison to dogs with SSS (indicating the role of parasympathetic modulation in this pathological condition), but higher than HF values observed in dogs presenting CMVD. Fujii \& Wakao (2003) found similar results using an experimental approach, where it was observed that control (healthy dogs) presented higher HF values in comparison to the same animals after the induction of mild mitral regurgitation. Oliveira et al. (2014) also observed that normal dogs presented significantly higher HF values than dogs with CMVD or those with heart failure. Therefore, it seems clear that the neurohumoral activation that follows a mitral disease decreases the parasympathetic modulation of the heart, which can be evaluated by HF values. The data are summarized in Table 9.

e) LF:HF ratio: This measurement is achieved by dividing LF by the HF values (normalized or not), and represents a good index to evaluate the sympatho-vagal balance on the heart.

Table 9. Summary results of selected studies from the literature, depicting the recording length for data acquisition and the HF values for healthy animals or those presenting pathophysiological conditions.

\begin{tabular}{|c|c|c|c|c|}
\hline Study & Species & $\begin{array}{l}\text { Recording } \\
\text { length }\end{array}$ & Healthy & Pathophysiological conditions \\
\hline Abbott (2005) & Feline & $4 \min$ & $\begin{array}{l}\text { Home: } 2.19 \text { ms }^{2} \text { (mean), } 0.18 \text { - } 31.72 \text { ms }^{2} \text { (range); } \\
\text { Hospital: } 1.16 \text { ms }^{2} \text { (mean), } 0.19-10.2 \mathrm{~ms}^{2} \text { (range) }\end{array}$ & - \\
\hline Alfonso et al. (2020) & Canine & $5 \mathrm{~min}$ & $79.52 \pm 14.08$ n.u. & CDK4: $69.75 \pm 16.36$ n.u. \\
\hline Baisan et al. (2020) & Canine & $5 \mathrm{~min}$ & 635 ms $^{2}$ (median), $932-2385$ ms $^{2}$ (95\% CI) & - \\
\hline $\begin{array}{l}\text { Bogucki \& Noszczyk- } \\
\text { Nowak (2017) }\end{array}$ & Canine & $3 \mathrm{~h}$ & $5845.45 \pm 2914.20 \mathrm{~ms}^{2}$ & \\
\hline Calvert \& Wall (2001) & Canine & $24 \mathrm{~h}$ & $61298 \pm 37695 \mathrm{~ms}^{2}$ & $\begin{array}{l}\text { mDCM: } 58800 \pm 29147 \mathrm{~ms}^{2}, \mathrm{sDCM}: \\
43240 \pm 26999 \mathrm{~ms}^{2}\end{array}$ \\
\hline Matsunaga et al. (2001) & Canine & $6 \mathrm{~h}$ & $1993 \pm 754 \mathrm{~ms}^{2}$ & - \\
\hline Minors \& O'Grady (1997) & Canine & $20 \min$ & $2589.1 \pm 663.9 \mathrm{~ms}^{2}$ & $\begin{array}{l}\text { oDCM: } 2205.1 \pm 752.11 \mathrm{~ms}^{2}, \mathrm{DCM}- \\
\text { CHF: } 9.68 \pm 6.9 \mathrm{~ms}^{2}\end{array}$ \\
\hline Oliveira et al. (2014) & Canine & $24 \mathrm{~h}$ & $19849.7 \pm 29563.5 \mathrm{~ms}^{2}$ & $\begin{array}{l}\text { MMVD: } 5301 \pm 6605 \mathrm{~ms}^{2} \\
\text { MMVD+HF: } 1972 \pm 3669.1 \mathrm{~ms}^{2}\end{array}$ \\
\hline Pirintr et al. (2017) & Canine & $14 \mathrm{~h}$ & $7204.9 \pm 1525.1 \mathrm{~ms}^{2}$ & MMVD: $8243.6 \pm 2323.2 \mathrm{~ms}^{2}$ \\
\hline
\end{tabular}

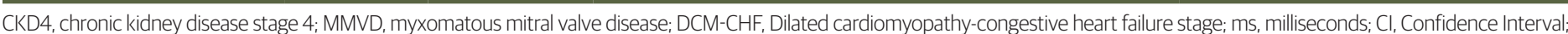

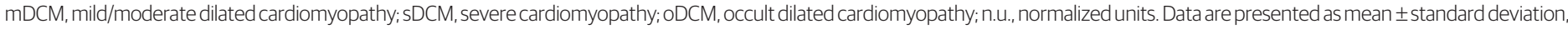
unless stated otherwise. 
Table 10. Summary results of selected studies from the literature, depicting the study, species, recording length for data acquisition, and the LF:HF ratio values for healthy animals or those presenting pathophysiological conditions (expressed as absolute units).

\begin{tabular}{|c|c|c|c|c|}
\hline Study & Species & $\begin{array}{l}\text { Recording } \\
\text { length }\end{array}$ & Healthy & Pathophysiological conditions \\
\hline Abbott (2005) & Feline & $4 \mathrm{~min}$ & $\begin{array}{c}\text { Home: } 0.63 \text { (mean), } 0.16 \text { - } 4.9 \text { (range); Hospital: } \\
1.65 \text { (mean), } 0.4 \text { - } 6.12 \text { (range) }\end{array}$ & - \\
\hline Alfonso et al. (2020) & Canine & $5 \mathrm{~min}$ & $0.28 \pm 0.25$ & CDK4: $0.48 \pm 0.32$ \\
\hline Baisan et al. (2O2O) & Canine & $5 \min$ & 0.99 (median), 1.07 - 1.68 (95\% CI) & - \\
\hline $\begin{array}{l}\text { Bogucki \& Noszczyk-Nowak } \\
\text { (2017) }\end{array}$ & Canine & $3 \mathrm{~h}$ & $0.25 \pm 0.11$ & $\begin{array}{l}\text { SSS: } 0.25 \pm 0.11 \\
\text { CMVD: } 0.4 \pm 0.13\end{array}$ \\
\hline Calvert and Wall (2001) & Canine & $24 \mathrm{~h}$ & $0.38 \pm 0.27$ & $\begin{array}{l}\text { mDCM: } 0.11 \pm 1.46 \\
\text { sDCM: } 0.24 \pm 1.38\end{array}$ \\
\hline Matsunaga et al. (2001) & Canine & $6 \mathrm{~h}$ & $0.164 \pm 0.029$ & - \\
\hline Minors \& O'Grady (1997) & Canine & $20 \mathrm{~min}$ & $0.354 \pm 0.156$ & $\begin{array}{l}\text { oDCM: } 0.825 \pm 0.519 \\
\text { DCM-CHF: } 15.1 \pm 5.88\end{array}$ \\
\hline Oliveira et al. (2014) & Canine & $24 \mathrm{~h}$ & $0.39 \pm 0.49$ & $\begin{array}{l}\text { MMVD: } 0.85 \pm 1.03 \\
\text { MMVD+HF: } 1.07 \pm 1.23\end{array}$ \\
\hline Pirintr et al. (2017) & Canine & $14 \mathrm{~h}$ & $0.44 \pm 0.06$ & MMVD: $1.01 \pm 0.16$ \\
\hline
\end{tabular}

SSS, sick sinus syndrome; CKD4, chronic kidney disease stage 4; MMVD, myxomatous mitral valve disease; $\mathrm{HF}$, heart failure; DCM-CHF, Dilated cardiomyopathy-chronic heart failure stage; CI, Confidence Interval; mDCM, mild/moderate dilated cardiomyopathy; SDCM, severe cardiomyopathy; oDCM, occult dilated cardiomyopathy. Data are presented as mean \pm standard deviation, unless stated otherwise

Again, this index does not represent the level of sympathetic or vagal output to the heart, but only the level of modulation (Task Force of the European Society of Cardiology, 1996; Shaffer \& Ginsberg, 2017). Matsunaga et al. (2001) showed a significant variation in the LF:HF ratio during the day (0.187 \pm 0.073 a.u.) and night (0.08 \pm 0.04 a.u.) for dogs, expressing the circadian influence on the autonomic modulation and LF:HF. Fujii \& Wakao (2003) measured the LF:HF ratio in dogs before $(0.323 \pm 0.1545$ a.u.) and after $(0.516 \pm 0.2821$ a.u.) the induction of a mild mitral regurgitation, observing an increase in the LF:HF ratio, thereby, indicating an increase in the sympathetic over parasympathetic modulation. Bogucki \& NoszczykNowak (2017) observed LF/HF ratio of 0.28 \pm 11 a.u. for clinically healthy dogs, $0.25 \pm 0.11$ a.u. for dogs presenting SSS, and 0.4 \pm 0.13 a.u. for dogs with CMVD. Oliveira et al. (2014) observed that the LF:HF ratio increased with the progression of cardiovascular disease, since healthy dogs presented lower LF:HF in comparison to dogs with stable CMVD and those with heart failure. Minors \& O'Grady (1997) and Calvert \& Wall (2001) evaluated the LF:HF ratio in Doberman Pinschers in normal or DCM conditions and observed that dogs expressing DCM presented an LF:HF ratio indicating a predominance of sympathetic modulation of the cardiovascular system. These data (Table 10) reveal the autonomic modulation imbalance that is caused by neurohumoral activation that follows the mitral valve disease, increasing sympathetic/decreasing parasympathetic modulation of the heart.

\section{Limitations of time domain methods:}

First, it should be recognized that HRV analysis (time or frequency domain method) does not provide a direct measurement of autonomic cardiac activity (only indirect). Therefore, any assumption should be made qualitatively and not quantitatively (Billman, 2011). The first limitation of time domain methods is that recordings with different lengths cannot be compared, as such recordings will result in very different measurements. In veterinary medicine, there are no established parameters for any of the time domain methods due to several reasons. In this regard, it is very important that veterinary researchers continue to publish their results so that, in the near future, we will be able to identify the real normal values for each time domain method. However, it is possible, and valuable, to evaluate the same animal with time domain methods (pre- and post-treatment or to evaluate the progress of a disease, for example). Moreover, for time 
domain analysis, all the heart beats in the time series must be "normal" (that is, all the ectopic beats should be removed from the time series) in order to reflect the effect of regulatory mechanisms on the sinoatrial node. Regarding the limitations of statistical methods, obtaining good-quality recordings is important; otherwise, automatic R-R identification by the analysis softwares would be flawed (Rajendra Acharya et al., 2006; Shaffer \& Ginsberg, 2017).

\section{Limitations of frequency-domain methods}

Regarding FFT, the first limitation is the need for interpolation methods to remove artifacts and/ or ectopic beats and avoid distortions in the measurements. The interpolation method used must consider the quality of data and the type of ectopic beat and specific artifacts (Li et al., 2019). FFT is not adequate for non-stationary data, and most biological signals are not. Therefore, there is a need to adopt processing steps to make the data stationary (Task Force of the European Society of Cardiology, 1996; Shaffer \& Ginsberg, 2017; Li et al., 2019). The biggest limitation to FFT is that it fails to provide the exact location of an event in the time series. In order to make the signal stationary, FFT uses sufficiently short windows. Although it improves the frequency location of an event, it worsens the time location. If the window used is larger, the frequency location becomes worse, and the time location improves (Rajendra Acharya et al., 2006; Wallisch et al., 2009). In addition, the measured value for each specific frequency band depends on the length of the recording; therefore, there is a need to choose an appropriate recording length to make the results comparable. When using AR, most of the limitations arise from the non-suitability for non-stationary data and the need of a suitable model, making it difficult to compare the data (Task Force of the European Society of Cardiology, 1996; Shaffer \& Ginsberg, 2017; Li et al., 2019). Although the LF frequency component has been widely used for estimating sympathetic modulation of the heart, this frequency band also carries parasympathetic and other regulatory component information; therefore, some authors suggest that the LF component cannot be used as an index of sympathetic regulation (Billman, 2011). Moreover, experimental data suggest that there are situations where HRV analysis does not yield an estimate of autonomic modulation of the heart: For example, Piccirillo et al. (2009) observed that, in an experimental model of pacedinduced chronic heart failure (CHF), HRV analysis was a good marker of autonomic nervous system modulation of the heart in normal conditions. However, in situations that lead to a decrease in the responsiveness of the sinus node to sympathetic activity (such as CHF), HRV analysis may not represent autonomic balance on the heart.

\section{Additional and future HRV analysis methods}

There are several additional methods that have been used for HRV analysis, but we will focus on the most important and promising ones for veterinary medicine.

a) Wavelet transform (WT): Similar to FFT, WT represents a linear transformation of the ECG signal (Belova et al., 2007). WT solves the location problem of the FFT because it provides a comparatively better frequency and time resolution of an event. The basic fact is that the wavelets are located in space and time, and this does not occur for the trigonometric functions used in Fourier analysis (Morettin, 1999; Wallisch et al., 2009). Therefore, wavelet analysis is suitable for the analysis of non-stationary signals, whereas Fourier transform is not. Wavelet analysis is performed by decomposing the ECG tachogram or periodogram in scaled versions of a "mother function" (defined as an a priori). Using this method, WT measures the similarity between the signal and the version of the scaled mother function, resulting in coefficients such as FFT (Belova et al., 2007). WT provides information about the occurrence of a certain event in time and frequency (scale). For FFT, in wavelet analysis, specific frequency bands represent regulatory components of the cardiovascular system. However, there are very few clinical studies in small animals; most of the available studies in dogs and cats using WT to address cardiac modulation are still experimental (for example, see Jiménez et al. (2004) and Lee et al. (2020).

b) Approximate entropy (ApEn): In a method developed by Pincus (1991), ApEn is a measure of the complexity and regularity of a time series, detrending underlying patterns in an apparently random sequence of events (Rajendra Acharya et al., 2006; Billman, 2011; Shaffer \& Ginsberg, 2017). Since the cardiac oscillator is not a sine wave generator, HRV displays a random and 
non-linear behavior (Billman, 2011), making ApEn more suitable to evaluate HRV than FFT or AR analysis. The main advantage of this method is that it can be successfully applied to short and noisy datasets. It exhibits higher values for higher HRV and lower values for cardiac diseases featuring lower HRV (Rajendra Acharya et al., 2006). There is a general lack of clinical studies in small animal veterinary medicine regarding ApEn, but few experimental studies have provided reference values. For example, Palazzolo et al. (1998) observed an ApEn of 1.65 \pm 0.09 in resting healthy dogs and a significantly lower value for hypotensive dogs (0.99 \pm 0.25$)$, suggesting that the neurohumoral activation occurring in hypotensive states reduces HRV and, therefore, ApEn. Another non-linear method has been developed to evaluate the complexity of HRV, sample entropy (SampEn), which is very similar to ApEn but has a simpler calculation. When the dataset is large, ApEn is equal to SampEn (Rajendra Acharya et al., 2006).

\section{Conclusions}

HRV analysis tools provide a simple, non-invasive, and accessible tool for the evaluation of autonomic modulation of the cardiovascular system. By using these techniques, it is possible to infer the seriousness of a cardiovascular disease and the success of a cardiovascular pharmacological treatment. Like any other tool, HRV analysis methods present limitations that must be considered. The use of these techniques in veterinary clinical practice on a daily basis yields information about cardiovascular modulation in normal and pathophysiological states, which may provide a better understanding of cardiac pathologies in small animals, as well as better treatment protocols.

\section{Ethics statement}

None.

\section{Financial support}

None.

\section{Conflicts of interest}

None.

\section{Authors' contributions}

LGF - Wrote the manuscript, reviewed critically for relevant intellectual content, approved the final version, agreed to be responsible for all aspects of the work assuring that questions related to the accuracy or integrity of any part of the work. FACS - Wrote the manuscript, reviewed critically for relevant intellectual content, approved the final version, agreed to be responsible for all aspects of the work assuring that questions related to the accuracy or integrity of any part of the work.

The study was carried out at Departamento de Ciências Fisiológicas do Instituto de Ciências Biológicas e da Saúde da Universidade Federal Rural do Rio de Janeiro.

\section{References}

Abbott, J. A. (2005). Heart rate and heart rate variability of healthy cats in home and hospital environments. Journal of Feline Medicine and Surgery, 7(3), 195-202. http://dx.doi.org/10.1016/i.jfms.2004.12.003. PMid:15922226.

Akselrod, S., Gordon, D., Ubel, F. A., Shannon, D. C., Berger, A. C., \& Cohen, R. J. (1981). Power spectrum analysis of heart rate fluctuation: A quantitative probe of beat-to-beat cardiovascular control. Science, 213(4504), 220-222. http://dx.doi.org/10.1126/science.6166045. PMid:6166045.

Alfonso, A., Le Sueur, A. N. V., Geraldes, S. S., Guimarães-Okamoto, P. T. C., Tsunemi, M. H., Santana, D. F., Ribeiro, V. R. F., Melchert, A., Chiacchio, S. B., \& Lourenço, M. L. G. (2020). Heart rate variability and electrocardiographic parameters predictive of arrhythmias in dogs with Stage IV chronic kidney disease undergoing intermittent haemodialysis. Animals: an Open Access Journal from MDPI, 10(10), 1829.

Altimiras, J. (1999). Understanding autonomic sympathovagal balance from short-term heart rate variations. Are we analyzing noise? Comparative Biochemistry and Physiology. Part A, Molecular \& Integrative Physiology, 124(4), 447-460. http://dx.doi.org/10.1016/S1095-6433(99)00137-3. PMid:10682243. 
Altimiras, J., Feliu, M., Aissaoui, A., \& Tort, L. (1994). Computing heart rate variability using spectral analysis techniques: HRVUAB, a ready-to-use program. Computer Applications in the Biosciences, 10(5), 559-562. http:// dx.doi.org/10.1093/bioinformatics/10.5.559. PMid:7828074.

Baisan, R. A., Condurachi, E. I., \& Vulpe, V. (2020). Short-term heart-rate variability in healthy small and mediumsized dogs over a five-minute measuring period. Journal of Veterinary Research, 64(1), 161-167. http://dx.doi. org/10.2478/jvetres-2020-0013. PMid:32258813.

Belova, N. Y., Mihaylov, S. V., \& Piryova, B. G. (2007). Wavelet transform: A better approach for the evaluation of instantaneous changes in heart rate variability. Autonomic Neuroscience, 131(1-2), 107-122. http://dx.doi. org/10.1016/j.autneu.2006.07.006. PMid:16942920.

Billman, G. E. (2011). Heart rate variability - A historical perspective. Frontiers in Physiology, 2(86), 86. PMid:22144961.

Blake, R. R., Shaw, D. J., Culshaw, G. J., \& Martinez-Pereira, Y. (2018). Poincaré plots as a measure of heart rate variability in healthy dogs. Journal of Veterinary Cardiology, 20(1), 20-32. http://dx.doi.org/10.1016/j. jvc.2017.10.006. PMid:29277470.

Bogucki, S., \& Noszczyk-Nowak, A. (2017). Short-term heart rate variability in dogs with sick sinus syndrome or chronic mitral valve disease as compared to healthy controls. Polish Journal of Veterinary Sciences, 2O(1), 167-172. http://dx.doi.org/10.1515/pjvs-2017-0021. PMid:28525326.

Borgarelli, M., Ferasin, L., Lamb, K., Bussadori, C., Chiavegato, D., D’Agnolo, G., Migliorini, F., Poggi, M., Santilli, R. A., Guillot, E., Garelli-Paar, C., Toschi Corneliani, R., Farina, F., Zani, A., Dirven, M., Smets, P., Guglielmini, C., Oliveira, P., Di Marcello, M., Porciello, F., Crosara, S., Ciaramella, P., Piantedosi, D., Smith, S., Vannini, S., Dall'Aglio, E., Savarino, P., Quintavalla, C., Patteson, M., Silva, J., Locatelli, C., \& Baron Toaldo, M. (2020). DELay of Appearance of sYmptoms of Canine Degenerative Mitral Valve Disease Treated with Spironolactone and Benazepril: The DELAY Study. Journal of Veterinary Cardiology, 27, 34-53. http://dx.doi.org/10.1016/j. jvc.2019.12.002. PMid:32032923.

Calvert, C. A., \& Wall, M. (2001). Effect of severity of myocardial failure on heart rate variability in Doberman Pinschers with and without echocardiographic evidence of dilated cardiomyopathy. Journal of the American Veterinary Medical Association, 219(8),1084-1088. http://dx.doi.org/10.2460/javma.2001.219.1084. PMid:11700705.

Fujii, Y., \& Wakao, Y. (2003). Spectral analysis of heart rate variability in dogs with mild mitral regurgitation. American Journal of Veterinary Research, 64(2), 145-148. http://dx.doi.org/10.2460/ajvr.2003.64.145. PMid:12602581.

Gianfranchesco Filippi, M., de Castro Ferreira Lima, M., Paes, A. C., Sarita Cruz Aleixo, A., Oba, E., Ferreira de Souza, F., Kiomi Takahira, R., \& Gomes Lourenço, M. L.. (2019). Evaluation of heart rate variability and behavior of electrocardiographic parameters in dogs affected by chronic Monocytic ehrlichiosis. PLoS One, 14(5), eO216552. PMid:31125348.

Hezzell, M. J., Sleeper, M., Ferrari, J., \& Arndt, J. (2018). Sample size determination for evaluation of time domain heart rate variability indices in canine lameness. Journal of the American Animal Hospital Association, 54(5), 235-238. http://dx.doi.org/10.5326/JAAHA-MS-6533. PMid:30040442.

Jiménez, R. F., Günther, B., \& Torres, P. (2001). Time-frequency analysis of arterial pressure oscillations in anesthetized dogs: Effects of standardized hemorrhages. Shock (Augusta, Ga.), 15(2), 143-150. http://dx.doi. org/10.1097/00024382-200115020-00011. PMid:11220643.

Jiménez, R. F., Torres, P., Günther, B., Morgado, E., \& Jiménez, C. A. (2004). Wavelet and Fourier analysis of ventricular and main arteries pulsations in anesthetized dogs. Biological Research, 37(3), 431-447. http://dx.doi. org/10.4067/S0716-97602004000300008. PMid:15515968.

Lee, S., Khrestian, C. M., Sahadevan, J., \& Waldo, A. L. (2020). Reconsidering the multiple wavelet hypothesis of atrial fibrillation. Heart Rhythm,17(11), 1976-1983. http://dx.doi.org/10.1016/i.hrthm.2020.06.017. PMid:32585192.

Li, K., Rüdiger, H., \&Ziemssen, T. (2019). Spectral analysis of heart rate variability: time window matters. Frontiers in Neurology, 10, 545. http://dx.doi.org/10.3389/fneur.2019.00545. PMid:31191437.

Matsunaga, T., Harada, T., Mitsui, T., Inokuma, M., Hashimoto, M., Miyauchi, M., Murano, H., \& Shibutani, Y. (2001). Spectral analysis of circadian rhythms in heart rate variability of dogs. American Journal of Veterinary Research, 62(1), 37-42. http://dx.doi.org/10.2460/ajvr.2001.62.37. PMid:11197557.

Minors, S. L., \& O'Grady, M. R. (1997). Heart rate variability in the dog: Is it too variable? Canadian Journal of Veterinary Research, 61(2), 134-144. PMid:9114965.

Morettin, P. A. (1999). Ondas e Ondaletas. Da análise de Fourier à análise de Ondaletas de Série Temporais. São Paulo: EDUSP.

Oliveira, M. S., Muzzi, R. A. L., Araújo, R. B., Muzzi, L. A. L., Ferreira, D. F., \& Silva, E. F. (2014). Heart rate variability and arrhythmias evaluated with Holter in dogs with degenerative mitral valve disease. Arquivo Brasileiro de Medicina Veterinária e Zootecnia, 66(2), 425-432. http://dx.doi.org/10.1590/1678-41626097.

Palazzolo, J. A., Estafanous, F. G., \& Murray, P. A. (1998). Entropy measures of heart rate variation in conscious dogs. The American Journal of Physiology, 274(4), H1099-H1105. PMid:9575912.

Piccirillo, G., Ogawa, M., Song, J., Chong, V. J., Joung, B., Han, S., Magrí, D., Chen, L. S., Lin, S. F., \& Chen, P. S. (2009). Power spectral analysis of heart rate variability and autonomic nervous system activity measured directly in healthy dogs and dogs with tachycardia-induced heart failure. Heart Rhythm, 6(4), 546-552. http://dx.doi. org/10.1016/j.hrthm.2009.01.006. PMid:19324318. 
Pincus, S. M. (1991). Approximate entropy as a measure of system complexity. Proceedings of the National Academy of Sciences of the United States of America, 88(6), 2297-2301. http://dx.doi.org/10.1073/pnas.88.6.2297. PMid:11607165.

Pirintr, P., Saengklub, N., Limprasutr, V., Sawangkoon, S., \& Kijtawornrat, A. (2017). Sildenafil improves heart rate variability in dogs with asymptomatic myxomatous mitral valve degeneration. The Journal of Veterinary Medical Science, 79(9), 1480-1488. http://dx.doi.org/10.1292/jvms.17-0016. PMid:28717064.

Rajendra Acharya, U., Paul Joseph, K., Kannathal, N., Lim, C. M., \& Suri, J. S. (2006). Heart rate variability: a review. Medical \& Biological Engineering \& Computing, 44(12), 1031-1051. http://dx.doi.org/10.1007/s11517-006-0119-0. PMid:17111118.

Shaffer, F., \& Ginsberg, J. P. (2017). An overview of heart rate variability metrics and norms. Frontiers in Public Health, 5, 258. http://dx.doi.org/10.3389/fpubh.2017.00258. PMid:29034226.

Spier, A. W., \& Meurs, K. M. (2004). Assessment of heart rate variability in Boxers with arrhythmogenic right ventricular cardiomyopathy. Journal of the American Veterinary Medical Association, 224(4), 534-537. http:/l dx.doi.org/10.2460/javma.2004.224.534. PMid:14989545.

Task Force of the European Society of Cardiology. (1996). Heart rate variability. Standards of measurement, physiological interpretation, and clinical use. European Heart Journal, 17(3), 354-381.

Wallisch, P., Lusingnan, M. E., Benayoun, M. D., Baker, T. I., Dickey, A. S., \& Hastopoulos, N. G. (2009). Frequency analysis Part II: Nonstationary signals and spectrograms. In P. Wallisch, M. E. Lusingnan \& M. D. Benayoun. MATLAB for neuroscientists an introduction to scientific computing in MATLAB (pp. 117-124). Cambridge: Academic Press. 